\title{
HOMOGENEOUS ALGORITHM FOR CALCULATING THE FLOW OF A VISCOUS SUPERSONIC JET INTO A SUBMERGED SPACE
}

\author{
Institute of Technical Mechanics \\ of the National Academy of Sciences of Ukraine and the State Space Agency of Ukraine \\ 15 Leshko-Popel St., 49005,Dnipro,Ukraine; e-mail:itm12@ukr.net
}

This paper presents a marching algorithm for the numerical solution of "viscous layer" equations (simplified Navier-Stokes equations in which the second derivatives with respect to the longitudinal coordinate are dropped and dissipative terms in the equation for the radial velocity component are discarded) to calculate the turbulent flow in a multicomponent supersonic jet of a rocket engine outflowing into a submerged space or a subsonic cocurrent air flow. In this algorithm, the equations are divided into two groups. The first group includes the equations for the longitudinal momentum component, energy, gas mixture component transfer, and turbulence characteristics. These equations are of the parabolic type, and they can be solved with a marching method by an implicit absolutely stable iterative scheme using scalar marching. The second group includes the equation for the radial momentum component and the continuity equation. In combination with the state equation, these equations are considered as equations in the pressure and the transverse velocity component. An algorithm for solving this group of equations is formulated. In this algorithm, a tridiagonal matrix system of equations for the grid values of the pressure is formed in solving the equations of the second group. A boundary-value problem is formulated for this system: the radial coordinate derivative of the pressure on the jet axis is zero, and the pressure on the jet boundary is set equal to that in the submerged space or in the concurrent subsonic flow. The solution of this problem is used in the determination of the pressure in the supersonic flow region. In the outer subsonic part of the jet, the pressure is put to be equal to that in the outflow space. The transverse velocity component in the super- and the subsonic part of the jet is determined using a relation that results from the difference approximation of the continuity equation.

The use of the proposed marching algorithm in the calculation of a rocket engine jet outflowing into a submerged space allows a continuous transition from a nonisobaric fully supersonic flow at the nozzle outlet to a subsonic flow in the jet to the point of its compete mixing with the air in the outflow space.

To verify the proposed algorithm, the results calculated thereby are compared with experimental data.

Keywords viscous layer approximation, marching algorithm, supersonic jet of a rocket engine, concurrent subsonic flow, submerged space.

1. Rodionov A. V. A new marching method for computing jets of combustion products. Computational Mathematics and Mathematical Physics. 2002. V. 42, No. 9. Pp. $136-1371$.

2. Sofronov A. V. The method of calculation of the jets of combustion product at the rocket launch (in Russian). Physical- Chemical Kinetics in Gas Dynamics. 2006. V 4. URL: htpp//chemphys.edu.ru/2006-10-23001.pdf

3. Galitseisky K. B. Simulation of high-velocity turbulent jet after-burning (in Russian). Fizika Goreniya i Vzryva. 2006. V.42, No. 2. Pp. 3-9.

4. Tymoshenko V. I., Belotserkovets I. S. Marching flow calculation in the interaction of a supersonic turbulent jet with a subsonic bounded concurrent flow (in Russian). Visnyk Dnipropetrovskoho Universytetu. 2008. V. 1. No. 1. Pp. 15-23.

5. Sekundov A. N. Application of a differential equation for turbulent viscosity to the analysis of plane nonself-similar flows. Fluid Dynamics. 1971. No. 5. Pp. 828-840.

6. Meshcheryakov E. A.., Levin V. M., Sabelnikov V. A. Computational and experimental study of the burning of a hydrogen jet in a supersonic cocurrent air flow in a channel (in Russian). Trudy TsAGI. - 1983. - No. 2193. $-36 \mathrm{pp}$.

7. Godunov S. K. Ryabenki V. S. Theory of Difference Schemes: An Introduction (in Russian). Moscow: Nauka, 1973. - 400 pp.

8. Timoshenko V. I., Deshko H. Ye. Numerical simulation of efflux of a supersonic multicomponent chemical reacting rocket engine jet (in Russian). Kosm. Nauka Tehnol. 2017. V. 23, No. 6. Pp. 3-11

9. Glushko G. S., Ivanov I. E., Kryukov I. A. Turbulence modeling for supersonic jet flows (in Russian). Physical-Chemical Kinetics in Gas Dynamics. 2010. V. 9. URL: www.chemphys.edu.ru/pdf/2010-01-12-023.pdf. 10. Seiner J.M., Norum T.D., Experiments of shock associated noise on supersonic jets. AIAA Pap. 79-1526, 1979 . 